\title{
Classic Tuberculous Meningoencephalitis manifestations, without lumbar puncture
}

\author{
Andi Kurnia Bintang, Tio Andrew Santoso, \\ Muhammad Yunus Amran, Muhammad Akbar
}

\section{CASE REPORT}

A 28-year-old man who was hospitalized with decreased consciousness.Consciousness decreased slowly since one week before being admitted to our hospital. He had headache since two months ago but became worse since two weeks ago. There were frequent nausea and vomiting for the last two months (approximately four times daily). $\mathrm{He}$ was often confused, had abnormal personal behaviour, and had

Andi Kurnia Bintang ${ }^{1}$, Tio Andrew Santoso ${ }^{2}$, Muhammad Yunus Amran ${ }^{3}$, Muhammad Akbar ${ }^{4}$

Affiliations: ${ }^{1}$ Clinical Associate Professor and Lecturer, Department of Neurology, Medical Faculty of Hasanuddin University, Dr. WahidinSudirohusodo General Hospital, and Hasanuddin University Teaching Hospital, Jl. PerintisKemerdekaan KM 11, Makassar, South Sulawesi; ${ }^{2}$ Clinical Fellow, Department of Neurology, Medical Faculty of Hasanuddin University, Dr. WahidinSudirohusodo General Hospital, and Hasanuddin University Teaching Hospital, JI. PerintisKemerdekaanKM 11, Makassar, South Sulawesi; ${ }^{3} \mathrm{Clinical}$ Assistant Professor and Lecturer, Department of Neurology, Medical Faculty of Hasanuddin University, Dr. WahidinSudirohusodo General Hospital, and Hasanuddin University Teaching Hospital, Jl. PerintisKemerdekaanKM 11, Makassar, South Sulawesi; ${ }^{4}$ Chief of Department, Department of Neurology, Medical Faculty of Hasanuddin University, Dr. WahidinSudirohusodo General Hospital, and Hasanuddin University Teaching Hospital, Jl. PerintisKemerdekaanKM 11, Makassar, South Sulawesi.

Corresponding Author: Muhammad Yunus Amran, MD, PhD, Neurologist, Lecturer and Clinical Assistant Professor, Department of Neurology, Medical Faculty of Hasanuddin University, Dr. Wahidin, Sudirohusodo General Hospital, and Hasanuddin University Teaching Hospital, Jl. PerintisKemerdekaan KM 11, Makassar, 90245, Indonesia; Email: yunusamran10@gmail.com

Received: 14 February 2018

Accepted: 29 March 2018

Published: 16 April 2018 double vision since two months ago.He often had fever, night sweat, and weight losssince two months ago. He had chronic cough since two months ago. His appetite was decreased. There was no history of head trauma, hypertension, diabetes, high blood cholesterol level, stroke and heart disease. Family history of chronic cough or tuberculosis treatment was denied. Based on physical and neurological examination, he was subfebrile (his temperature was $37.5^{\circ} \mathrm{C}$ ) with Glasgow Coma Scale (GCS) score total of $11\left(\mathrm{E}_{3} \mathrm{M}_{5} \mathrm{~V}_{3}\right)$. Nuchal rigidity and Kernig's sign were positive. Movement and strength were unclear lateralization at first, but then we found that there was decreased movement and strenght at the right side of the body, tone and physiological reflexes were normal. Pathological reflexes were negative. Routine and chemistry blood examination demonstrated White Blood Cell (WBC): $13.940 / \mathrm{mm}^{3}$; Red Blood Cell (RBC): 4.55 $\times 10^{6} / \mathrm{mm}^{3} ;$ Hemoglobin (Hb): $13.3 \mathrm{~g} / \mathrm{dl}$; Haematocrit (HCT): 38.1\%; Platelet (PLT): $323 \times 10^{3} /$ $\mathrm{mm}^{3}$; Blood Random Glucose: $90 \mathrm{mg} / \mathrm{dl}$; Ureum 18 $\mathrm{mg} / \mathrm{dl}$; Creatinine: $0.52 \mathrm{mg} / \mathrm{dl}$; SGOT: $40 \mathrm{mg} / \mathrm{dl}$; SGPT: $79 \mathrm{mg} / \mathrm{dl}$; Sodium: $126 \mathrm{mmol} / \mathrm{L}$; Potassium: 4,1 mmol/L; Chloride: $90 \mathrm{mmol} / \mathrm{L}$; HIV Rapid Test non reactive; HIV Antigen 0.03 (non reactive); and HIV Antibody 0.04 (non reactive). Axial head CT-scans of both non-contrast and contrast to the administration of intravenous gadolinium (Gd-DOTA) were performed and showed left thalamus infarct that was not enhanced by contrast injection and hypertensive hydrocephalus (obstuctive) (Figure 1A and B). A contrast head CT-Scan examination showed basal enhancing exudate (Figure 2). A chest X-Ray examination showed old and active lung tuberculosis with wide lesion and left pleural reaction (Figure 3). A non contrast thoracic CT-Scan showed old and active lung tuberculosis with wide lesion (Data was not shown).

The patient was treated with Four-drug fixed Dose Combinations (4FDC) (Tuberculous regimen consists of Isoniazid $75 \mathrm{mg}$, Rifampicin $150 \mathrm{mg}$, Pyrazinamide 400 $\mathrm{mg}$, and Ethambutol $275 \mathrm{mg}$ ) as much as 4 tablets/24 hours/oralwith additional Isonoazid $100 \mathrm{mg} / 24$ hours/ oral, Streptomycin $1000 \mathrm{mg} / 24$ hours/intramuscular for two months followed by Isoniazid $400 \mathrm{mg} / 24$ hours/oral 


\section{EDORIUM Journals}

and Rifampicine $600 \mathrm{mg} / 24$ hours/oral for 10 months. We also treated the patient with Intravenous Dexamethasone 10mg (initial dose) continue with $5 \mathrm{mg} / 6$ hours for two weeks (we did tappered off per three days). We consulted the patient to neurosurgery department for ventriculoperitoneal (VP) shunt procedure but his family refused it. We also consulted the patient to pulmonology department and they establised the Diagnosis of Lung Tuberculosis. Lumbar Puncture was contra-indicated because he had papilledema on Ophthalmoscopy examination (resulted from Hydrocephalus). He responded well to the treatment and was discharged on the $23^{\text {rd }}$ day of care with good condition and no sequele of neurologic deficit.

\section{DISCUSSION}

Tuberculous Meningoencephalitis (TBM) is rare form of tuberculous extrapulmonal manifestation and it is a subacute central nervous system infection (CNS) infection from the primary focus of the lungs. Delays in seeking medical care, diagnosis, and treatment are contributing factors to the high mortality and morbidity [1]. TBM

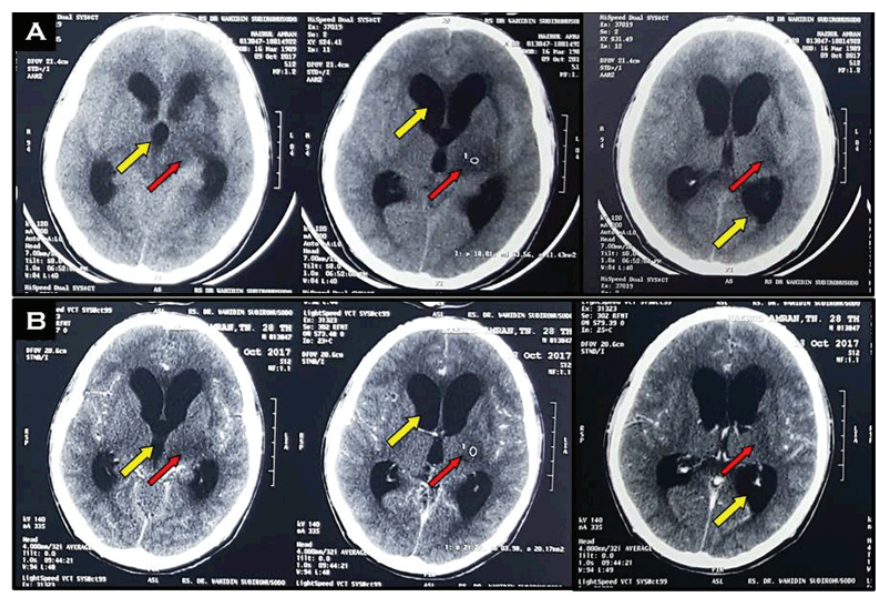

Figure 1(A and B): Axial section of Head CT Scan without (A) and with (B) contrast, showedhyodense lession in left thalamus that not enhanced by contrast injection (red arrows), reffered to a left thalamus infarction. Yet, both of them showed non communicans hydrocephalus (yellow arrows).

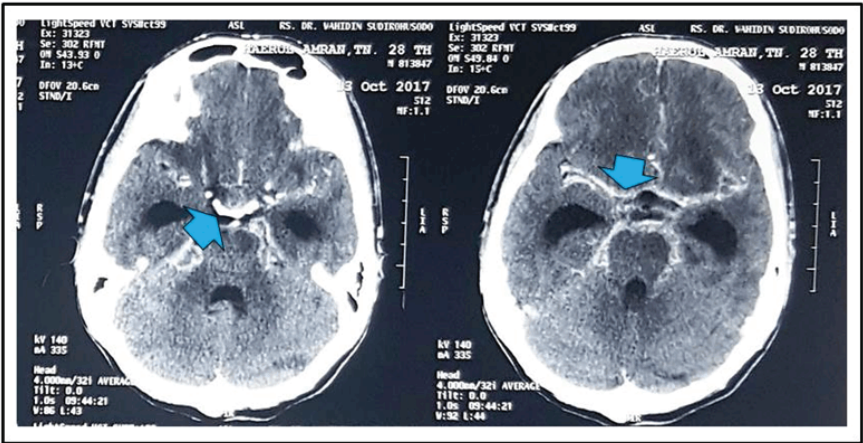

Figure 2: Contrast axial section of Head CT Scan showed basal exudate enhancement corresponded to the acummulation of thick exudate in the basal cisterns (blue arrows).

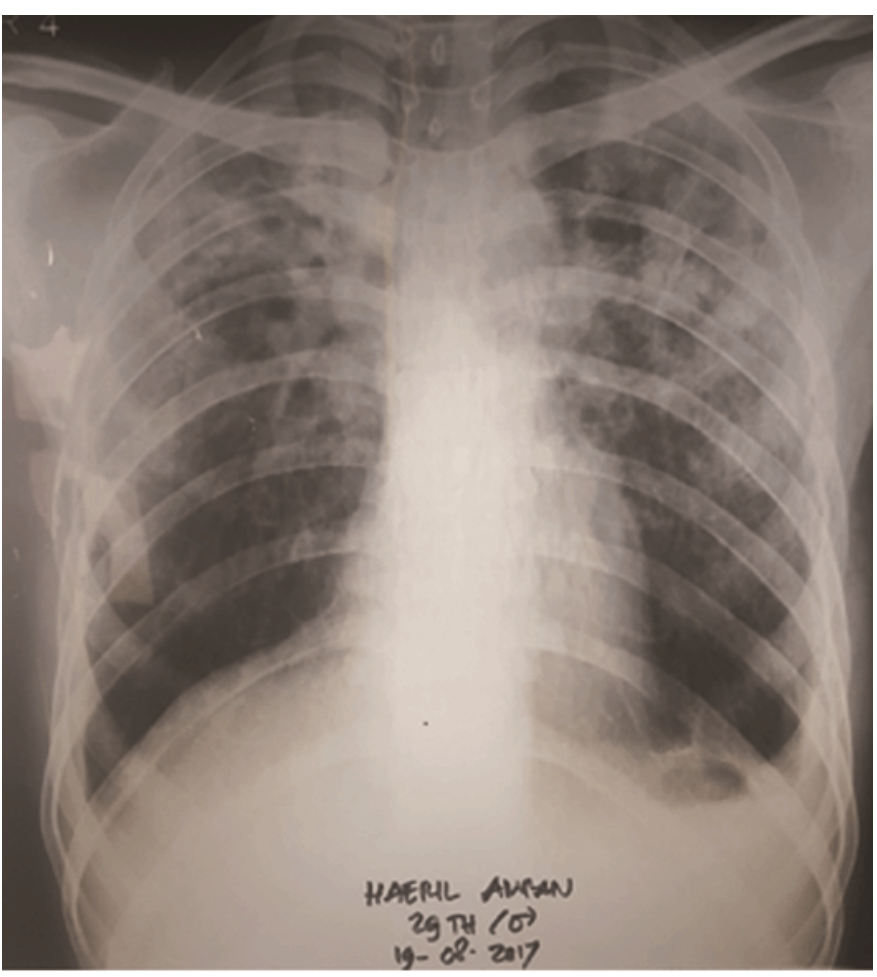

Figure 3: Chest X-Ray showed increased opacity on both lungs with fibrotic line which retracts both hillus and diaphragm, reffered to old and active lung Tuberculosis with wide lesion.

accounted for $5,2 \%$ of all cases of extrapulmonary TB and $0.7 \%$ of all cases of TB. TBM complicates approximately 1 of every 300 untreated primary TB infections [2]. The etiology of Tuberculous Meningitis is Mycobacterium tuberculosis Hominis type which are obligate aerobic, slowly growing, acid-fast bacillus external hydrophobic layer (abundant in lipids and glycolipids in the cell wall) that interferes with antibiotic penetration, thus explaining its difficult and lengthy therapy [3,4]. A prodromal phase of low-grade fever, headache, malaise, vomiting, dizziness, and/or personality changes may persist for a few weeks, after that the patients can develop more severe headache, altered mental status, stroke, hydrocephalus, cranial neuropathies (II, III, IV, VI, VII, VIII), and hemiparese [5]. History of tuberculosis is found in only approximately $10 \%$ of patients. The presence of concurrent active pulmonary tuberculosis on chest $\mathrm{X}$ ray ranges from 30 to $50 \%$ [6]. Based on the history taking, physical and neurological examination, we could conclude that the patient suffered from second stage of tuberculous meningitis (According to British Medical Research Council: GCS score 11-15/drowsy, altered mental status, signs of meningeal irritation, cranial nerve palsy of III, IV, VI) [6]. The patient had headache, fever, vomiting, abnormal personal behavioural and confusion that persisted for two months, after that he had altered mental status and right hemiparese. He ever had double vision that we suggested him to have cranial neuropathies (III, IV, VI), but unfortunately, we couldn't 


\section{EDORIUM Journals}

find any abnormalities in the eye movement. He also had nuchal rigidity, chronic cough, night sweat, weight loss, and lung Tuberculosis on Chest X-Ray Examination. The diagnosis of TBM can be difficult and may be based only on clinical and cerebrospinal fluid (CSF) findings without definitive microbiologic confirmation. Certain clinical characteristics such as sub-acute duration of symptoms (>six days), moderate CSF pleiocytosis, and the presence of focal deficits increase the probability of TBM diagnosis. Characteristic CSF findings of TBM include the following: Clear or xantochrome appearance, lymphocytic-predominant pleiocytosis (100 and 500 cells $/ \mu \mathrm{L}$ ), elevated protein levels (150 and $200 \mathrm{mg} /$ $\mathrm{dL}$ ), low glucose (less than $45 \mathrm{mg} / \mathrm{dL}$ or CSF: plasma ratio <0.5), increased opening pressure. Definitive microbiology examination such as acid-fast smear and CSF culture ( gold standard) have low sensitivity and took time (approximately 8 weeks). Given the relatively low sensitivity of acid-fast smear and delay in culture, newer diagnostic methods for TBM have been more recently developed, such as ELISA, PCR, and Xpert MTB [1, 3, 4, 5]. Unfortunately, we didn't perform Lumbar Puncture (LP) examination to the patient because there was a contraindication. From the Opthalmoscopy examination, the patient had papilledema that resulted from elevated intracranial pressure due to Hydrocephalus that could cause herniation and mortality. We consulted the patient to Pulmonology Department and they planned to do sputum examination. Unfortunately, we couldn't find any specimen because the patient had no cough when he was admitted to the hospital so they conducted Thorax CT-scan and established the diagnose of Lung Tuberculosis. Head CT-scan without contrast may be normal, later complications may be visible including hydrocephalus or infarcts due to arteritis. A number of additional features following contrast administration may be visible: such as basal enhancing exudates, leptomeningeal enhancement, along sylvian fissures, tentorium uncommonly convexities. Cerebral infarction in TBM involved especially the perforators and terminal cortical branches. These infarcts mainly involved the lateral lenticulostriate arteries, medial lenticulostriate arteries, and perforators from posterior cerebral artery [7, 8]. Head CT-scan without contrast of the patient showed infarct in the left thalamus and Hydrocephalus. Infarct in the left thalamus is probably caused by the vasculitis affecting the perforators branch from posterior cerebral artery that supply the left thalamus. Head CT-scan with contrast showed basal enhancing exudates. The imaging examination supported the Tuberculous Meningitis diagnosis. We have to establish the diagnosis as soon as possible and start the treatment immediately. Timely treatment dramatically improves the outcome of TBM. Empiric treatment is warranted when clinical features and CSF findings are suggestive of TBM even before microbiologic confirmation. The recommended treatment regimen for presumed drug susceptible TBM consists of two months of daily INH, rifampin (RIF), pyrazinamide
(PZA), and either streptomycin (SM), or ethambutol (EMB), followed by 7-10 months of INH and RIF $[9,10]$. We treated the patient with the TB regimen. We gave Isoniazid with a dose of $400 \mathrm{mg} /$ day, Rifampicin with a dose of $600 \mathrm{mg} /$ day, Pyrazinamide with a dose of $25 \mathrm{mg} /$ $\mathrm{kgBW} /$ day (1250 mg/day), Ethambutol with a dose of 15 $\mathrm{mg} / \mathrm{kgBB} /$ day (750 mg/day), and Streptomycin 30mg/ $\mathrm{kgBB} /$ day ( $\max 1000 \mathrm{mg} /$ day). Patients with TBM receive adjunctive corticosteroids regardless of disease severity at presentation to reduce exudate production in the basal area, to prevent adhesive, necrosis and blockage of spinal block. We treated the patient with Dexamethasone $10 \mathrm{mg}$ (loading dose) continued with $5 \mathrm{mg} / 6$ hours/intravenous (tapering off per 3 days) for 2 weeks. Prognosis of TBM especially depends on neurologic status at the time of presentation, and time-to-treatment initiation.The advanced age, consciousness disturbance, low GCS score on admission and concomitant hydrocephalus are independent risk factors of TBM prognosis [11]. The prognosis of the patient was good. Although the patient admitted to the hospital with second stage of TBM and had complication of Hydrocephalus and Infarct of the Left Thalamus, but he responded well to the medication and there were no sequelae of neurological deficit when he was discharged from the hospital.

The diagnosis of TBM can be difficult and may be based only on clinical and preliminary cerebrospinal fluid (CSF) findings without definitive microbiologic confirmation. Definitive microbiologic examination such as fast-acid smear and culture (Gold Standard) are slow and has low sensitivity and slow. Treatment should be at least nine months in duration and should be consisted of at least four agents of Tuberculous drug regimen.

\section{CONCLUSION}

Meningitis is the one of the extrapulmonary manifestations and most deadly form of tuberculosis (TB). Early diagnosis and prompt treatment can dramatically reduce the high mortality and morbidity associated with this disease. Adjunctive corticosteroid treatment should be considered, particularly in persons without concurrent HIV infection, to reduce exudate production in the basal area, to prevent adhesive, necrosis and blockage of spinal block.

\section{REFERENCES}

1. Chin JH. Tuberculous meningitis: Diagnostic and therapeutic challenges. Neurol Clin Pract 2014 Jun;4(3):199-205.

2. Garcia-Monco JC, Ruiz-Ojeda J. CNS Tuberculosis and other mycobacterial infections. In: Garcia-Monco JC, editor. CNS Infection: A Clinical Approach. Switzerland: Springer-Verlag; 2014. p. 139-50.

3. Thwaites G, Chau TT, Mai NT, Drobniewski F, McAdam K, Farrar J. Tuberculous meningitis. J 


\section{EDORIUM Journals}

Neurol Neurosurg Psychiatry 2000 Mar;68(3):28999.

4. Ropper AH, Samuels MA, Klein JP. Infections of the Nervous System (Bacterial, Fungal, Spirochetal, Parasitic) and Sarcoidosis. Adams and Victor's Principles of Neurology. 10th Edition. Volume 1. New Yor: McGraw Hill Education; 2014. p. 717-9.

5. Marx GE, Chan ED. Tuberculous meningitis: Diagnosis and treatment overview. Tuberc Res Treat 2011;2011:798764.

6. Rock RB, Olin M, Baker CA, Molitor TW, Peterson PK. Central nervous system tuberculosis: Pathogenesis and clinical aspects. Clin Microbiol Rev 2008 Apr;21(2):243-61.

7. Imaging in CNS Tuberculosis. 2015. [Available at: https://emedicine.medscape.com/article/344862overview]

8. Tai MS, Viswanathan S, Rahmat K, et al. Cerebral infarction pattern in tuberculous meningitis. Sci Rep 2016 Dec 13;6:38802.

9. World Health Organization. Fixed-dose combination tablets for the treatment of tuberculosis: Report of an informal meeting held in Geneva, 27 April 1999. [Available at: http://www.who.int/tb/publications/ fixed-dosecombination-report/en/]

10. World Health Organization. Guidelines for treatment of drug-susceptibletuberculosis and patient care (2017 update). [Available at: http://www.who.int/tb/ publications/2017/dstb_guidance_2017/en/]

11. Gu J, Xiao H, Wu F, Ge Y, Ma J, Sun W. Prognostic factors of tuberculous meningitis: A single-center study. Int J Clin Exp Med 2015 Mar 15;8(3):4487-93.

$* * * * * * * * *$

Keywords: Glasgow coma scale, Lumbar puncture, Tuberculous meningoencephalitis

\section{How to cite this article}

Bintang AK, Santoso TA, Amran MY, Akbar M. Classic Tuberculous Meningoencephalitis manifestations, without lumbar puncture. Int $\mathrm{J}$ Case Rep Images 2018;9:100905Zo1AB2018.

Article ID: 100905Z01AB2018 doi: 10.5348/100905Z01AB2018CL

$* * * * * * * * *$

\section{Author Contributions}

Andi Kurnia Bintang - Substantial contributions to conception and design, Acquisition of data, Analysis and interpretation of data, Drafting the article, Revising it critically for important intellectual content, Final approval of the version to be published

Tio Andrew Santoso - Substantial contributions to conception and design, Acquisition of data, Analysis and interpretation of data, Drafting the article, Revising it critically for important intellectual content, Final approval of the version to be published

Muhammad Yunus Amran - Substantial contributions to conception and design, Acquisition of data, Analysis and interpretation of data, Drafting the article, Revising it critically for important intellectual content, Final approval of the version to be published

Muhammad Akbar - Substantial contributions to conception and design, Acquisition of data, Analysis and interpretation of data, Drafting the article, Revising it critically for important intellectual content, Final approval of the version to be published

\section{Guarantor of Submission}

The corresponding author is the guarantor of submission.

\section{Source of Support}

None

\section{Consent Statement}

Written informed consent was obtained from the patient for publication of this clinical image.

\section{Conflict of Interest}

Authors declare no conflict of interest.

\section{Copyright}

(C) 2018 Andi Kurnia Bintang et al. This article is distributed under the terms of Creative Commons Attribution License which permits unrestricted use, distribution and reproduction in any medium provided the original author(s) and original publisher are properly credited. Please see the copyright policy on the journal website for more information. 


\section{ABOUT THE AUTHORS}

Article citation: Bintang AK, Santoso TA, Amran MY, Akbar M. Classic Tuberculous Meningoencephalitis manifestations, without lumbar puncture. Int J Case Rep Images 2018;9:100905Zo1AB2018.

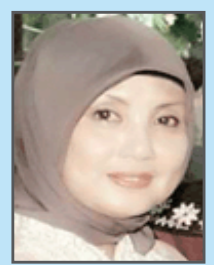

Andi Kurnia Bintang is Clinical Associate Professor and Lecturer at Department of Neurology, Medical Faculty of Hasanuddin University, Dr. Wahidin Sudirohusodo General Hospital, and Hasanuddin University Teaching Hospital, Jl. Perintis Kemerdekaan KM 11, Makassar, South Sulawesi. She earned the undergraduate degree of Medical Doctor from Medical Faculty of Hasanuddin University, Makassar, Indonesia and also for Master Degree in Master of Hospital Administration (MARS). Doctoral degree she got from Hasanuddin University Postgraduate Program, Makassar, Indonesia. She also a Neurologist and Consultant of Neuro-ophthalmologist and Neuro-otology.

Email: a.kurnia_b@yahoo.co.id

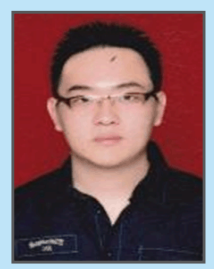

Tio Andrew Santoso is Clinical Fellow at Department of Neurology, Medical Faculty of Hasanuddin University, Dr. Wahidin Sudirohusodo General Hospital, and Hasanuddin University Teaching Hospital, Jl. Perintis Kemerdekaan KM 11, Makassar, South Sulawesi, Indonesia.

Email: andrew.santoso.as@gmail.com

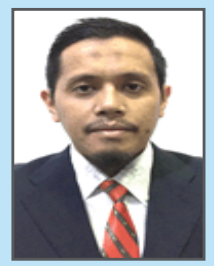

Muhammad Yunus Amran is Clinical Assistant Professor and Lecturer at Department of Neurology, Medical Faculty of Hasanuddin University, Dr. Wahidin Sudirohusodo General Hospital, and Hasanuddin University Teaching Hospital, Jl. Perintis Kemerdekaan KM 11, Makassar, South Sulawesi, Indonesia. He earned the undergraduate degree of Medical Doctor from Medical Faculty of Hasanuddin University, Makassar, Indonesia. Philosophy of Doctoral degree (PhD) he got from Kyushu University, Postgraduate Program, and Fukuoka. Japan. He also a Neurologist and Fellowship In Pain Management (FIPM), New Delhi, India. He is very interesting in Interventional Pain Management, Interventional neuroradiology and neuro intervention and Neuro-endovascular therapy.

Email: yunusamran10@gmail.com

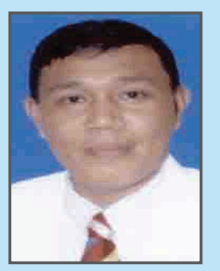

Muhammad Akbar is Chief of Department, Department of Neurology, Medical Faculty of Hasanuddin University, Dr. Wahidin Sudirohusodo General Hospital, and Hasanuddin University Teaching Hospital, Jl. Perintis Kemerdekaan KM 11, Makassar, South Sulawesi, Indonesia. He earned the undergraduate degree of Medical Doctor from Medical Faculty of Hasanuddin University, Makassar, Indonesia. Philosophy of Doctoral degree (PhD) he got from Hiroshima University, Postgraduate Program, and Hiroshima. Japan. He also a Neurologist and Consultant of Neuro-vascular and Stroke. Email: akbar8ofkuh@gmail.com

Access full text article on other devices

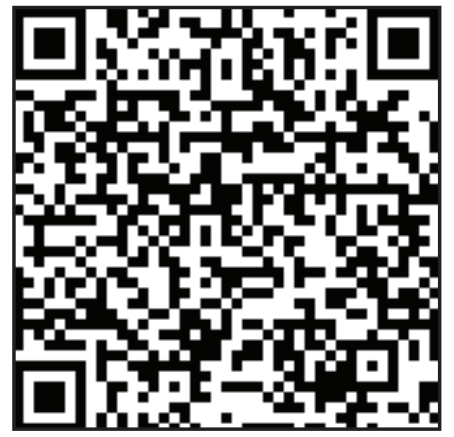

Access PDF of article on other devices

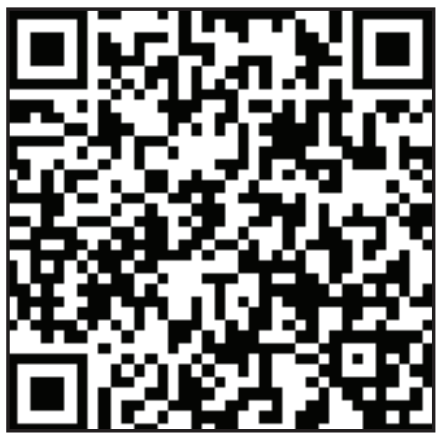

